\title{
Modelling of dried apple rehydration indices using ANN**
}

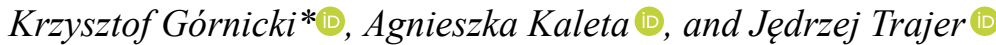 \\ Department of Fundamental Engineering, Faculty of Production Engineering, Warsaw University of Life Sciences - SGGW, \\ Nowoursynowska 164, 02-787 Warsaw, Poland
}

Received June 21, 2018; accepted December 22, 2018

\begin{abstract}
The purpose of the research was to study the effect of different drying and rehydration conditions on the rehydration indices of apple and to model the rehydration indices of apple using artificial neural networks. The research involved the examination of the rehydration process of $10 \mathrm{~mm}$ apple cubes, which were dried in natural convection (drying air velocity), forced convection and fluidization at the following drying temperatures 50,60 and $70^{\circ} \mathrm{C}$. The process of rehydration was conducted in distilled water at the following temperatures 20, 45, 70 and $95^{\circ} \mathrm{C}$. Five rehydration indices were used to express rehydration. Artificial neural networks (MLP 3-5-1 and MLP 3-4-1) were used to make the rehydration indices dependent on both drying and rehydration parameters: drying temperatures, $v$ and following temperatures. Five statistical tools, i.e. correlation coefficient, mean bias error, root mean square error, reduced chi-square, and t-statistic method ( $t$-stat), were applied to determine the fit. To identify critical parameters and their impact on the ANN outputs, a sensitivity analysis (backward stepwise method) was performed.

Keyw ords: rehydration, rehydration indices, apple, quality, ANN
\end{abstract}

\section{INTRODUCTION}

Drying is the most popular method for the preservation of agricultural products such as fruit, vegetables, herbs or spices, as it ensures the microbiological safety of various biological materials. This method has several disadvantages and limitations. Contact between the material being dried and hot air causes the degradation of key flavour compounds and nutritional substances. Besides, there is also a risk of volatile compound separation during the drying process (Silva et al., 2017). Undesirable changes in product colour, possibly due to Maillard reactions, may be

*Corresponding author e-mail: krzysztof_gornicki@sggw.pl

**This work was supported from research project No. N N 313

780940 from the Polish National Science Centre (2011-2014). observed in the food materials being processed (Figiel et al., 2010). Numerous researchers have attempted to study the influence of drying on the quality of various agricultural products, thereby confirming the importance of additional thorough studies in this area (Karam et al., 2016).

Dehydrated products may be used in many processed or ready-to-eat foods instead of fresh foods due to such advantages as the convenience of transportation, storage, preparation and use. Some dehydrated products must be rehydrated before consumption or further processing (Nayak et al., 2006).

Rehydration is the process of moistening dry material. Three main processes take place simultaneously during rehydration: imbibition of water into the dried material, swelling of the material and leaching of solubles (Moreira et al., 2008). It is a very complex phenomenon that involves different physical mechanisms such as water imbibition, internal diffusion, convection at the surface and within large open pores, as well as the loosening of the solid matrix. Capillary imbibition is very important during the early stages, leading to an almost instantaneous uptake of water. Tension effects between the liquid and the solid matrix may also be relevant. In the rehydration process, two main crosscurrent mass fluxes occur, a water flux from the rehydrating solution to the product, and a flux of solutes (sugars, acids, minerals, vitamins) from the food product to the solution, with the kinetics depending on the immersion medium (Górnicki et al., 2013).

(C) 2019 Institute of Agrophysics, Polish Academy of Sciences (c) (1) () $\Theta$ 
Some of these factors induce changes in the structure and composition of the plant tissue, which results in the impairment of the reconstitution properties. Therefore, equilibrium moisture content at saturation does not reach the moisture content of the raw materials prior to dehydration, indicating that the dehydration procedure is irreversible. Physical and chemical changes that take place during drying affect the quality of the dehydrated product, and merely by the simple addition of water, the properties of the raw material cannot be restored. Rehydration cannot be simply treated as the reverse process of dehydration. Hence, rehydration may be considered as a measure of the damage to the material caused by drying and the treatment preceding dehydration (Witrowa-Rajchert, 1999).

The process of rehydration is one of the most important quality properties of dried products, and should be rapid and complete. The fact that some dehydrated products are eventually consumed rehydrated, e.g. in milk, yoghurt, fruit juices, sucrose or glucose solutions or in instant soups and ready to eat meals, is another important reason for studying food rehydration processes, due to the importance of these processes in the development of these kinds of products (Maldonado et al., 2010). The achievement of a better understanding of rehydration processes seems to be crucial for the quality improvement of both dehydrated and rehydrated products, as well as for the production of new products (Seguí et al., 2013). Many researchers claim that the drying method used has the most significant impact on the rehydration process (Benseddik et al., 2018; Lewicki and Wiczkowska, 2006; Said et al., 2015; Stępień, 2008).

Rehydration is influenced by intrinsic factors: product chemical composition, pre-drying treatment, drying techniques and conditions, post-drying procedure, etc., and extrinsic factors: the composition of the immersion media, temperature and hydrodynamic conditions (Rastogi et al., 2004). A knowledge of the rehydration kinetics of dried products is important for the optimization of processes in terms of quality, since rehydration is a key quality aspect for the dried products that have to be reconstituted before their consumption (Garcia-Pascual et al., 2006). Rehydration indices and mathematical models of the rehydration process (empirical, semi-empirical, and theoretical) are reviewed and systematized (Górnicki, 2011).

A cluster analysis is a set of different algorithms, which group objects into clusters. Methods of cluster analysis are used in the data-mining phase when there are no a priori hypotheses. In the cluster analysis phase, two algorithms were used, i.e., the $k$-means algorithm, and the EM (Expectation-Maximization or Estimation-Maximization) algorithm. The foundation of the $k$-means algorithm (Hartigan, 1975) is relatively simple: given the specified number (desirable or hypothetically assumed) of $k$ clusters, the observations are assigned to clusters so that the means in the clusters differ as much as possible from one another in terms of distance. The methods applied in generalized clus- ter analysis using EM methods (Witten and Frank, 2005) constitute the extension of the above approach. Instead of assigning cases (observations) to clusters so that the differences between the means (quantitative variables) in groups are as great as possible, the EM algorithm calculates the probability of belonging to clusters assuming one or more probability distributions. The goal of the EM algorithm is the maximization of the overall probability (data credibility) for a given division into clusters, and, as opposed to the classic interpretation of $k$-means, the algorithm may be applied both for quantitative and qualitative variables.

An artificial neural network (ANN) is an information processing system, which learns from input/output data to determine the relationships between input/output data, and is used in pattern recognition, classification, etc. Unlike other modelling techniques (i.e. differential equations and regression equations), an ANN can handle more than two variables to predict two or more outputs. Regression equations or statistical models are subject to assumptions and cautions inherent in the analyses. ANNs are capable of correlating large and complex data sets. ANNs are used for their learning or adapting ability, and they do not require much knowledge of the underlying relationships between their input and output variables. The network learns both from the input and data, repeatedly. It can also approximate any continuous or discontinuous linear or nonlinear function. Therefore, such networks are very useful for modelling certain processes that are not yet completely understood (Mittal, 1996). Winiczenko et al. (2018) used a genetic algorithm and response surface methodology to optimize an ANN topology for predicting the colour change in rehydrated apple.

A disadvantage of artificial neural networks is the difficulty in the interpretation of the results it produces. The reliability of artificial intelligence often depends on its ability to explain the results obtained. Several methods have been proposed to overcome this disadvantage. These methods, i.e. sensitivity analysis (SA), are used to determine the degree of "sensitivity" of a given ANN to changes in the value of its parameters and its structure. Sensitivity coefficients describe changes in the ANN's outputs due to variations in the input parameters. A large sensitivity suggests that the ANN's performance can drastically change as a result of a small variation in a parameter. There are a few methods used to study the sensitivity of the ANN, for example: the "stepwise" method (Forward stepwise, Backward stepwise, Improved stepwise) (Gevrey et al., 2003), the "PaD" method (Dimopoulos et al., 1995), the "Profile" method (Lek et al., 1996), the "Weight" method (Garson, 1991).

The main aim of this work was to study the effect of different drying and rehydration conditions on the rehydration indices of apple, and to model the rehydration indices of apple using artificial neural networks. 


\section{MATERIALS AND METHODS}

Fresh, high-quality (Ligol) apples were purchased from a local store in Warsaw, Poland. Just before the drying experiments commenced, the apples were peeled, and the outer cortex was cut into cubes with thicknesses of $10 \pm 1 \mathrm{~mm}$. The initial moisture content of the fresh apple samples was approx. $85 \%$ w.b. (5.66 d.b.).

The following techniques were used to dry the raw material: natural convection with drying air velocity: $v=0.01 \mathrm{~m}$ $\mathrm{s}^{-1}$ (chamber dryer), forced convection with $v=\left\{0.5 \mathrm{~m} \mathrm{~s}^{-1}\right.$, $\left.2 \mathrm{~m} \mathrm{~s}^{-1}\right\}$ (tunnel dryer) and fluid bed drying with $v=6 \mathrm{~m}$ $\mathrm{s}^{-1}$ (laboratory-fluidized bed dryer) (Górnicki and Kaleta, 2007; Kaleta and Górnicki, 2010b; Kaleta et al., 2013b). The drying experiments were carried out at drying air temperatures $T_{d}=50,60$ and $70^{\circ} \mathrm{C}$ (the driers had an electric heater) in three replications until a constant mass of dried material was reached. The equilibrium moisture content of dried samples was about $9 \%$ w.b. (0.098 d.b.). The samples obtained from three independent drying experiments under the same drying conditions were randomly mixed, which produced 12 sample batches $\left(T_{d}=\{50,60,70\} \times v=\right.$ $\{0.01,0.5,2,6\})$. Each batch was stored for further studies in a tightly sealed container (not exposed to sunlight) for about one week at $20^{\circ} \mathrm{C}$.

The rehydration of dried apple was conducted in distilled water at temperature $T_{r}=20,45,70$, and $95^{\circ} \mathrm{C}$. Rehydration lasted from $6 \mathrm{~h}$ (at a medium temperature amounting to $20^{\circ} \mathrm{C}$ ) to $2 \mathrm{~h}$ (for $95^{\circ} \mathrm{C}$ ), and was carried out in triplicate. The initial mass of each dried sample subjected to rehydration was $10 \mathrm{~g}$, and the dried sample mass to water mass ratio at the beginning of the rehydration process was 1:20 (such a ratio was used very frequently in the literature (Femenia et al., 2000; Ravindra and Chattopadhyay, 2000; Winiczenko et al., 2018)). The water temperature was constant, and it was not stirred during rehydration.

The following indices were used to express rehydration. - Index $R I_{1}$ :

$$
R I_{1}=\frac{\text { mass of material after rehydration }}{\text { mass of dried material }} .
$$

Index $R I_{1}$ is the most common one used to describe rehydration characteristics. This index has been applied to describe the rehydration of amla (Verma and Gupta, 2004), apples (Jokić et al., 2009), button mushrooms (Askari et al., 2009), celery (Nowak et al., 2016), garlic (Sharma and Prasad, 2006), hawthorn fruits (Aral and Beşe, 2016), jackfruit (Kaushal and Sharma, 2016), kiwi (Ergün et al., 2016), lablab bean (Pervin et al., 2008), potatoes (Ravindra and Chattopadhyay, 2000), pumpkin (Seremet (Ceclu) et al., 2016), sea cucumbers (Zhang et al., 2016), soybean curd (Harnkarnsujarit et al., 2016), wormwood leaves (Beigi, 2017), and yam (Lin et al., 2007).

- Index $R I_{2}$ :

$$
R I_{2}=\frac{\text { mass of material after rehydration }}{\text { mass of raw material }} .
$$

This index has been applied to describe the rehydration of apple, parsley, potato (Lewicki 1998), cauliflower (Jayaramann et al., 1990), cabbage, carrot, celery, cucumber, eggplant, green onion, sword bean, horse radish, pepper, tomato (Zhang et al., 1994), chicken meat (Farkas and Singh, 1991).

- Index $R I_{3}$ :

$$
R I_{3}=\frac{\text { mass of water absorbed during rehydration }}{\text { mass of dried material }} .
$$

Index $R I_{3}$ has been applied to describe the rehydration of apples, kiwifruits, and tomatoes (Redgewell et al., 2008), bananas (Maskan, 2000), carrots (Doymaz, 2017), Chinese jujube (Fang et al., 2009), kiwifruits (Ergün et al., 2016), longan fruit (Nathakaranakule et al., 2010), potatoes (Cheng et al., 2006), and sweet potatoes (Antonio et al., 2008).

- Index $R I_{4}$ (formulated by the authors):

$$
R I_{4}=\frac{\text { mass of water in rehydrated material }}{\text { mass of water in the raw material }},
$$

- water absorption capacity WAC:

$$
\mathrm{WAC}=\frac{m_{r}\left(100-s_{r}\right)-m_{d}\left(100-s_{d}\right)}{m_{o}\left(100-s_{o}\right)-m_{d}\left(100-s_{d}\right)},
$$

where: $m$ is the mass $(\mathrm{kg}), s$ is the dry matter content (\%), and subscripts $d, o$, and $r$ refer to dry, before drying and rehydrated, respectively.

The WAC index was proposed by Lewicki (1998) and has been widely used to describe the rehydration of apples, parsley, and potatoes (Lewicki, 1998), apples (Atarés et al., 2008), carrots (Markowski and Zielińska, 2011), chestnuts (Moreira et al., 2008), mangoes (Link et al., 2017), Morchella esculenta (morel) (Garcia-Pascual et al., 2006), mushrooms (Garcia-Pascual et al., 2005), potatoes (Markowski et al., 2009), sesame seeds (Khazei and Mohammadi, 2009), and tomatoes (Lewicki et al., 2002).

The goal of the research was to analyse the impact of selected factors of the drying and dehydration process of selected products $\left(T_{d}, v, T_{r}\right)$ being studied on the quality indices (rehydration indices) of these products. Therefore, the results were searched to find cases that shared common factors according to their similarity with regards to the factors being analysed and the selected quality index.

The significance of the impact of $T_{d}, v$ and $T_{r}$ on the rehydration indices was determined using analysis of variance after accepting the uniformity test of Levene's variance. The Tukey test HSD was applied to divide the results into uniform groups (at the significance level of $p=0.05$ ). Calculations were carried out using the Statistica 12.5 application. 
ANN modelling was carried out with Matlab R2015a. The rehydration indices were predicted with feedforward multilayer perceptron artificial neural networks. In this study, the cases (the number depends on the index) were randomly divided into the following sets: for training - 70\% cases, for validation - $15 \%$ cases and for testing - $15 \%$ cases. Inputs: $T_{d}, v, T_{r}$ were normalized to obtain values within the range $0-1$. The values of the drying temperature, drying air velocity, rehydration temperature were normalized by dividing them by 70,6 , and 95 , respectively. The values of the rehydration indices (output) $R I_{1}$ and $R I_{3}$ were divided by 5 and 4 , respectively.

Statistical methods were used in order to find the most suitable model for the prediction of the rehydration indices of apple. The most frequently used of the statistical criteria from the literature for selecting the most suitable model are given below:

- Correlation coefficient R:

$$
\mathrm{R}^{2}=\frac{\sum_{i=1}^{N}\left(X_{i}-X_{p i}\right) \cdot \sum_{i=1}^{N}\left(X_{i}-X_{e i}\right)}{\sqrt{\left[\sum_{i=1}^{N}\left(X_{i}-X_{p i}\right)^{2}\right] \cdot\left[\sum_{i=1}^{N}\left(X_{i}-X_{e i}\right)^{2}\right]}},
$$

where: $X_{p, i}$ - is the $i$-th predicted value, $X_{e, i}-$ is the $i$-th experimental value, $N$ is the number of the observation.

The closer $\mathrm{R}$ is to 1 , the closer the relationship between the experimental and the predicted values. The discussed coefficient has been used by e.g. (Kaushal and Sharma, 2016):

- Mean bias error MBE:

$$
\mathrm{MBE}=\frac{1}{N} \sum_{i=1}^{N}\left(X_{p, i}-X_{e, i}\right) .
$$

The lower the values of MBE, the better the fit. This criterion has been used by e.g. (Kaleta and Górnicki, 2010a).

- Root mean square error RMSE (root mean square deviation RMSD):

$$
\operatorname{RMSE}=\left[\frac{1}{N} \sum_{i=1}^{N}\left(X_{p, i}-X_{\epsilon i}\right)^{2}\right]^{1 / 2} .
$$

Lower RMSE values indicate the better fit of the model. The root mean square error has been considered by e.g. (Beigi, 2017; Kaleta et al., 2013b):

- Reduced chi-square $\chi^{2}$ :

$$
\chi^{2}=\frac{\sum_{i=1}^{N}\left(X_{e, i}-X_{p, i}\right)^{2}}{N-n},
$$

where $n$ is the number of constants.

The lower the values of $\chi^{2}$, the better the fit. The discussed coefficient has been applied by e.g. (Aral and Beşe, 2016):

$-t$-statistic:

$$
\mathrm{t} \text {-stat }=\left[\frac{(n-1) \mathrm{MBE}^{2}}{\mathrm{RMSE}^{2}-\mathrm{MBE}^{2}}\right]^{1 / 2} .
$$

The smaller the criterion value, the better the model performance. $T$-stat has been considered by e.g. Kaleta and Górnicki (2010b).

To identify critical parameters and their degree of impact on the ANN outputs, a sensitivity analysis was performed. One of the most important methods in sensitivity analysis is the backward stepwise method, which consists of step-by-step adding or rejecting one input variable, and examining the effect on the output results. For instance, the largest value in RMSE or $\chi^{2}$ due to one input omission shows the most important input (Gevrey et al., 2003).

\section{RESULTS AND DISCUSSION}

Cluster analysis with the EM or $k$-means algorithm was used in the research, depending on the cluster size, i.e. the method capable of finding a larger cluster, was selected. The clusters found (one for each index) had high correlation coefficients (above 0.9). The cluster for the index $R I_{1}$ includes the cases, in which $T_{d} \in\left[50-70^{\circ} \mathrm{C}\right], v \in[0.01-2 \mathrm{~m}$ $\left.\mathrm{s}^{-1}\right], T_{r} \in\left[20-95^{\circ} \mathrm{C}\right]$. Clusters for indices $R I_{2}, R I_{3}$ and $R I_{4}$ include all cases, in which $T_{d} \in\left[50-70^{\circ} \mathrm{C}\right], v \in[0.01-6 \mathrm{~m}$ $\left.\mathrm{s}^{-1}\right], T_{r} \in\left[20-95^{\circ} \mathrm{C}\right]$, while the cluster for the WAC index includes the cases, in which $T_{d} \in\left[50-70^{\circ} \mathrm{C}\right], v \in\left[2-6 \mathrm{~m} \mathrm{~s}^{-1}\right]$, $T_{r} \in\left[20-95^{\circ} \mathrm{C}\right]$.

Table 1 shows the parameters of the drying and rehydration processes $\left(T_{d}, v, T_{r}\right)$ which produced the highest values of rehydration indices: $R I_{1}, R I_{2}, R I_{3}, R I_{4}$ and WAC. The apples dried in the tunnel dryer $\left(v=2 \mathrm{~m} \mathrm{~s}^{-1}\right)$ at $70^{\circ} \mathrm{C}$ and then rehydrated in distilled water at $70^{\circ} \mathrm{C}$ were characterized by the highest values of $R I_{1}, R I_{2}$, and $R I_{3}: 4.59$, 0.55 , and 3.59 , respectively. Dried apples obtained from the tunnel dryer $\left(v=0.5 \mathrm{~m} \mathrm{~s}^{-1}\right)$ at $70^{\circ} \mathrm{C}$ and then rehydrated at $45^{\circ} \mathrm{C}$ had the highest value of $R I_{4}(0.55)$, whereas for apples dried in a fluidized bed $\left(v=6 \mathrm{~m} \mathrm{~s}^{-1}\right)$ at $60^{\circ} \mathrm{C}$ and rehydrated at $70^{\circ} \mathrm{C}$ the value of WAC was the highest with a value of 0.50 .

Figures 1-3 show the impact of $T_{r}, T_{d}$ and $v$ on the following rehydration indices: $R I_{1}, R I_{2}, R I_{3}, R I_{4}$ and WAC. Parameter $v$ indicates the drying method.

Indices $R I_{1}$ and $R I_{2}$ are defined as the ratio of rehydrated material mass (the mass of the material following rehydration) to the mass of dried material and the material prior to drying, respectively (Eqs (1) and (2)). Irrespective of the drying method examined in the work, the obtained dried

Table 1. Parameters of drying and rehydration processes, which produced the highest values of rehydration indices

\begin{tabular}{cccc}
\hline \multirow{2}{*}{$\begin{array}{c}\text { Rehydration } \\
\text { index }\end{array}$} & \multicolumn{3}{c}{$\begin{array}{c}\text { Parameters of drying and rehydration } \\
\text { processes }\end{array}$} \\
\cline { 2 - 4 } & $T_{d}$ & $v$ & $T_{r}$ \\
\hline$R I_{1}$ & 70 & 2 & 70 \\
$R I_{2}$ & 70 & 2 & 70 \\
$R I_{3}$ & 70 & 2 & 70 \\
$R I_{4}$ & 70 & 0.5 & 45 \\
$\mathrm{WAC}$ & 60 & 6 & 70 \\
\hline
\end{tabular}




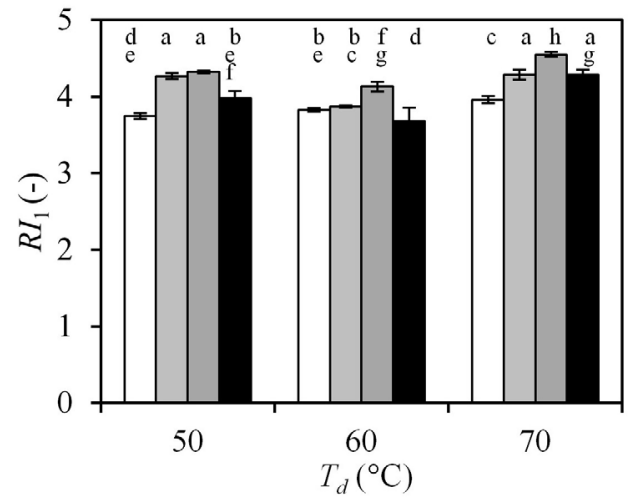

b

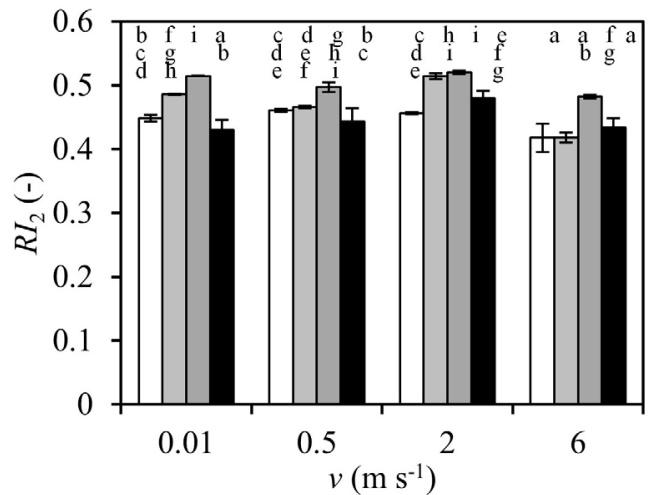

$\mathrm{c}$

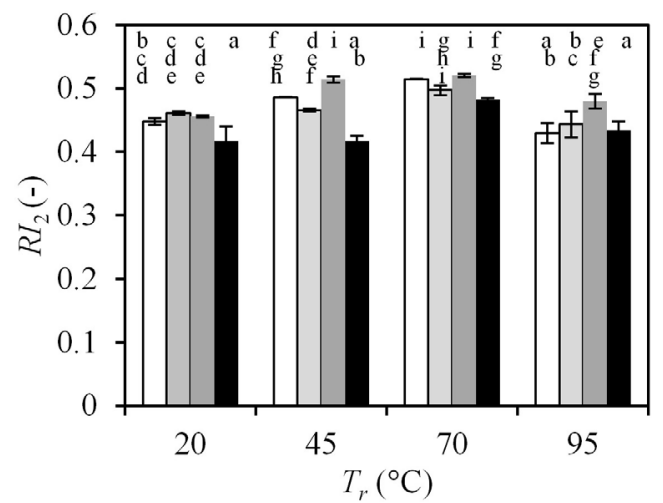

Fig. 1. Rehydration indices $R I_{1}$ and $R I_{2}$ for apple: a) dried at $v=0.5 \mathrm{~m} \mathrm{~s}^{-1}$, where: $\square-T_{r}=20^{\circ} \mathrm{C}, \square-T_{r}=45^{\circ} \mathrm{C}, \quad-T_{r}=70^{\circ} \mathrm{C}$, $-T_{r}=95^{\circ} \mathrm{C}$; b) dried at $T_{d}=60^{\circ} \mathrm{C}$, where: $\square-T_{r}=20^{\circ} \mathrm{C}$, $\left.-T_{r}=45^{\circ} \mathrm{C},-T_{r}=70^{\circ} \mathrm{C}, \square-T_{r}=95^{\circ} \mathrm{C} ; \mathrm{c}\right)$ dried at $T_{d}=60^{\circ} \mathrm{C}$, where: $\square-v=0.01 \mathrm{~m} \mathrm{~s}^{-1},-v=0.5 \mathrm{~m} \mathrm{~s}^{-1},-v=2 \mathrm{~m} \mathrm{~s}^{-1}, \square-v=6$ $\mathrm{m} \mathrm{s}^{-1}$. The same letters indicate homogenous groups $(\mathrm{p}<0.05)$.

material had a similar moisture content (and, consequently, mass). However, the drying method affected the extent of degradation changes and the drying temperature at the time when these changes occurred during the drying process (Lewicki and Wiczkowska, 2006). Therefore, the value of the indices being discussed is predominantly influenced by the mass of the obtained rehydrated material. This mass depends on the one hand on the amount of water absorbed, and on the other hand, on the amount of dry matter lost. Both of the masses depend on the magnitude of the degradation changes during drying but also on the conditions of the rehydration process. Increasing the rehydration temperature causes deterioration in the texture of the fruit, which compounds the damage caused during thermal dehydration and promotes a significant loss in the mechanical resistance of the samples. This excessive softening of the tissues alters the mass transfer ability of the system (Maldonado et $a l ., 2010)$. Consequently, the nature of the influence of the drying parameters and rehydration on the indices $R I_{1}$ and $R I_{2}$ being discussed is consistent with previously published results.

The impact of the drying temperature on indices $R I_{1}$ and $R I_{2}$ is not unequivocal (Fig. 1a). The increase in the drying temperature from 50 to $70^{\circ} \mathrm{C}$ results in an increase of the rehydration indices being discussed. However, the initial increase in $T_{d}$ from 50 to $60^{\circ} \mathrm{C}$ did not have any impact (e.g. for $T_{r}=20^{\circ} \mathrm{C}$ ) or even result in a decrease (e.g. for $\left.T_{r}=45^{\circ} \mathrm{C}\right)$ in the values of these indices. Further increases in the drying temperature (to $70^{\circ} \mathrm{C}$ ) resulted in an increase in the values of these indices, and they then reached the highest values. Jokić et al. (2009) stated that for rehydration at $20^{\circ} \mathrm{C}$ for dried apple (Florina) an increase in $T_{d}$ (from 50 to $70^{\circ} \mathrm{C}$ ) resulted in a decrease of $R I_{1}$.

The increase in the rehydration temperature to $70^{\circ} \mathrm{C}$ resulted in an increase in both the $R I_{1}$ and $R I_{2}$ indices (Fig. 1a,b). However, a further increase in $T_{r}$ to $95^{\circ} \mathrm{C}$ resulted in a decrease in the values of these indices, which even then reached values similar to those obtained at $T_{r}=20^{\circ} \mathrm{C}$ (e.g. $T_{d}=60^{\circ} \mathrm{C}$ ).

The drying air velocity does not have an unequivocal impact on both the $R I_{1}$ and $R I_{2}$ index (Fig. 1c). The increase in the flow of the drying air from 0.01 to $2 \mathrm{~m} \mathrm{~s}^{-1}$ did not have an impact on the indices being discussed (e.g. for $\left.T_{r}=20^{\circ} \mathrm{C}\right)$ nor did it influence their increase $(e . g$. for $\left.T_{r}=95^{\circ} \mathrm{C}\right)$. However, the values of the indices (e.g. for $T_{r}$ $20,45^{\circ} \mathrm{C}$ ) were the lowest for the rehydrated dried material obtained from the fluidized bed drier $\left(v=6 \mathrm{~m} \mathrm{~s}^{-1}\right)$. Jokić $e t$ $a l$. (2009) stated that for dried apple (Florina) rehydrated at $20^{\circ} \mathrm{C}$ an increase in $v$ (from 1.5 to $2.75 \mathrm{~m} \mathrm{~s}^{-1}$ ) resulted in an increase in $R I_{1}$.

Indices $R I_{3}$ and $R I_{4}$ are defined as the ratios of the mass of water absorbed in the rehydration process and the mass of water in the rehydrated material (the sum of the mass of water absorbed in the process of rehydration (this mass depends on the extent of degradation changes during drying but also on the conditions of the rehydration process (Maldonado et al., 2010)) and on the mass of water in the dried material) compared to the mass of the dried material and the mass of water in the material prior to drying, respectively (Eqs (3) and (4)). Similarly, as in the case of indices $R I_{1}$ and $R I_{2}$, the values of indices $R I_{3}$ and $R I_{4}$ are predominantly influenced by the mass of the absorbed water. Therefore, the influence of the drying parameters and rehydration on indices $R I_{3}$ and $R I_{4}$, is analogical. 
a

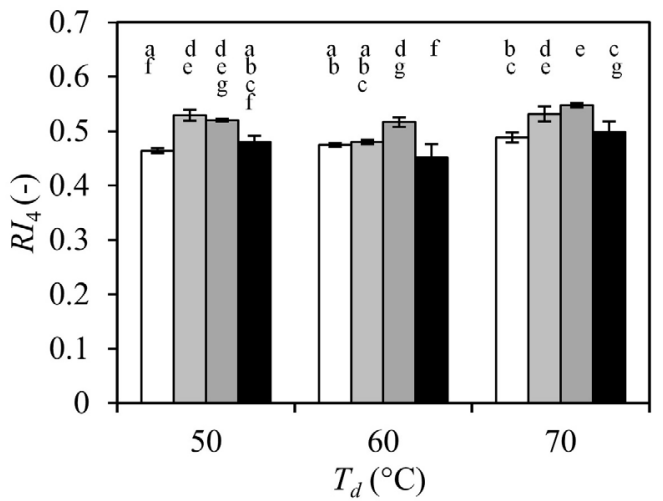

b

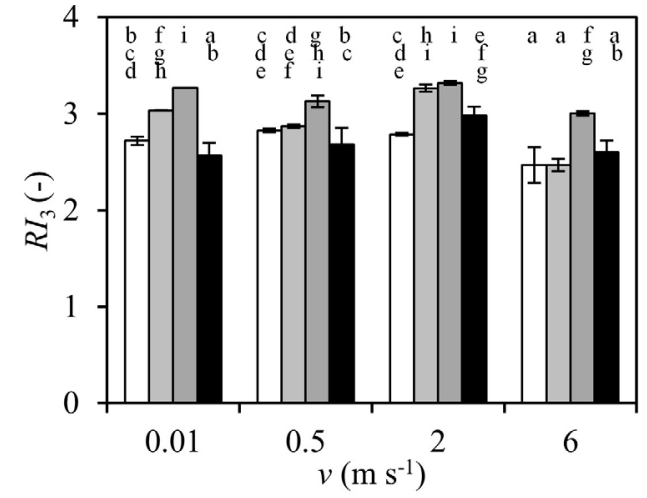

c



Fig. 2. Rehydration indices $R I_{3}$ and $R I_{4}$ for apple: a) dried at $v=0.5$ $\left.\mathrm{m} \mathrm{s}^{-1}, \mathrm{~b}\right)$ dried at $T_{d}=60^{\circ} \mathrm{C}, \mathrm{c}$ ) dried at $T_{d}=60^{\circ} \mathrm{C}$. Explanations as in Fig. 1.

The impact of the drying temperature on indices $R I_{3}$ and $R I_{4}$ is not unequivocal (Fig. 2a). The increase in the drying temperature from 50 to $70^{\circ} \mathrm{C}$ results in an increase in the rehydration indices being discussed. However, the initial increase in $T_{d}$ from 50 to $60^{\circ} \mathrm{C}$ did not have any influence (e.g. for $T_{r}=20^{\circ} \mathrm{C}$ ) or even resulted in a decrease (e.g. for $T_{r}=45^{\circ} \mathrm{C}$ ) in the values of these indices. Further increases in the drying temperature (to $70^{\circ} \mathrm{C}$ ) resulted in an increase in the values of these indices, which then reached their highest values.

An increase in the rehydration temperature to $70^{\circ} \mathrm{C}$ resulted in an increase in both the $R I_{3}$ and $R I_{4}$ indices (Fig. 2a, b). However, a further increase in $T_{r}$ to $95^{\circ} \mathrm{C}$ result-

ed in a decrease in the values of these indices, which even then reached values similar to those obtained at $T_{r}=20^{\circ} \mathrm{C}$ (e.g. $T_{d}=60^{\circ} \mathrm{C}$ ).

Drying air velocity does not have an unequivocal impact on both the $R I_{3}$ (Fig. 2c) and $R I_{4}$ index. An increase in the flow of the drying air from 0.01 to $2 \mathrm{~m} \mathrm{~s}^{-1}$ either did not have any impact on the indices being discussed (e.g. for $\left.T_{r}=20^{\circ} \mathrm{C}\right)$ or resulted in their increase $\left(\right.$ e.g. for $\left.T_{r}=95^{\circ} \mathrm{C}\right)$. However, the values of the indices obtained in the process of rehydration of previously dried material from the fluidized bed drier $\left(v=6 \mathrm{~m} \mathrm{~s}^{-1}\right)$ were generally lower (especially for smaller $T_{r}: 20,45^{\circ} \mathrm{C}$ ) than for the dried material obtained from other driers used in the study.

The WAC rehydration index (Eq. (5)) is defined as the ratio of the mass of water absorbed in the process of rehydration to the mass of water removed from the material in the process of drying. Obtaining a value of $\mathrm{WAC}=1$ means that the same amount of water that was removed from the material during drying was absorbed during rehydration. The WAC rehydration index depends on both the rehydration temperature and the drying air velocity. The increase in the rehydration temperature resulted in an increase in the WAC index or did not cause any changes in the index (Fig. 3) within the rehydration temperature range $20-70^{\circ} \mathrm{C}$. Similarly, as in the case of the rehydration indices

a

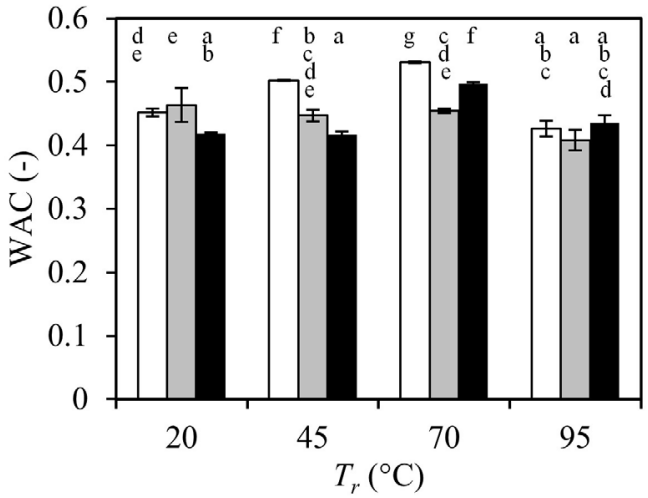

b

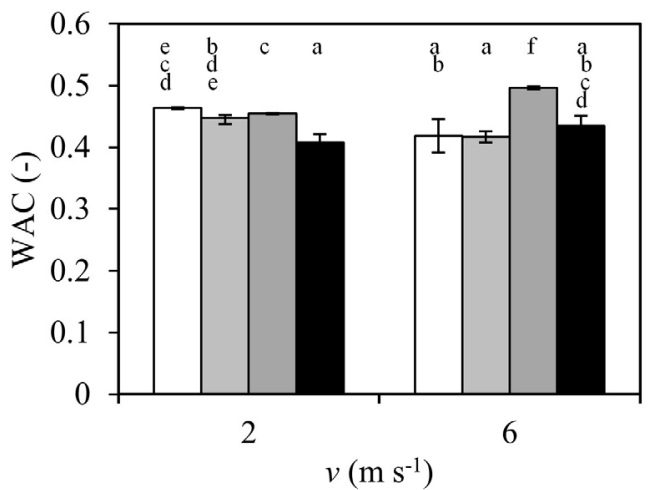

Fig. 3. WAC rehydration index for apple: a) dried at $T_{d}=60^{\circ} \mathrm{C}$, where: $\square-v=0.01 \mathrm{~m} \mathrm{~s}^{-1},-v=2 \mathrm{~m} \mathrm{~s}^{-1}, \boldsymbol{\square}_{-v}=6 \mathrm{~m} \mathrm{~s}^{-1}$; b) dried at $T_{d}=60^{\circ} \mathrm{C}$, where: $\square-T_{r}=20^{\circ} \mathrm{C},-T_{r}=45^{\circ} \mathrm{C},-T_{r}=70^{\circ} \mathrm{C}$, $-T_{r}=95^{\circ} \mathrm{C}$. The same letters indicate homogenous groups $(\mathrm{p}<0.05)$. 
$\left(R I_{1}-R I_{4}\right)$ discussed above, for the highest examined rehydration temperature $\left(T_{r}=95^{\circ} \mathrm{C}\right)$, this index reached a lower value (statistically significant differences $\mathrm{p}<0.05$ ) than for $T_{r}=70^{\circ} \mathrm{C}$ and $T_{r}=20^{\circ} \mathrm{C}$ (with the exception of the rehydration of the material dried in the fluidized bed drier). Lewicki (1998) obtained a slightly lower value of WAC (compared to the one obtained in this work): 0.396 .

Kaleta et al. (2013a) did not reveal the statistically significant impact of the drying temperature on the loss of dry mass of the material, or the impact of the selected drying method (free convection, forced convection, fluidized bed drying) on the final value of the dry mass loss of dried apples as a result of rehydration. For the rehydration of apples of the Idared variety, Witrowa-Rajchert (2003), dried them using three methods, i.e. convection, convection-microwave, and freeze-drying showed that the lowest dry mass loss was observed for apples dried using the sublimation method, for the two other drying methods similar results were obtained. Cubes of apples of the Gala variety, dried using the combined method, which involves initial drying by convection, and a further drying process using the microwave-vacuum method, demonstrated a greater capacity to retain dry mass than the apples dried using the convection method (Figiel, 2007). Rząca (2009) did not reveal significant differences in dry mass loss during the rehydration of apples of the Idared variety, dried using the following methods: convection, microwave-convection, and radiation-convection. Jokić (2009) observed that at the air velocity of $2.75 \mathrm{~m} \mathrm{~s}^{-1}$, the rehydration ratio $v s$. different drying temperatures $\left(50,70^{\circ} \mathrm{C}\right)$ was higher compared to that at the air velocity of $1.5 \mathrm{~m} \mathrm{~s}^{-1}$. Statistical analysis showed, however, that a drying temperature of $60^{\circ} \mathrm{C}$ for the selected air velocities had no statistically significant influence on the rehydration ratio $(\mathrm{p}<0.05)$.

Mass increment of dried apples during rehydration depends on the rehydration temperature (Kaleta et al., 2014). The higher the temperature, the faster the increment and the higher the final mass of the sample after rehydration. Simultaneously, at a temperature of $95^{\circ} \mathrm{C}$, the final mass of the rehydrated sample is similar to the final mass of the sample rehydrated at a temperature of $45^{\circ} \mathrm{C}$. The lowest final loss of dry substance was recorded for dried apples rehydrated at a temperature of $20^{\circ} \mathrm{C}$, while for samples rehydrated at $T_{r} 45,70$ and $95^{\circ} \mathrm{C}$ the values of the final dry substance loss were similar. The influence of the rehydration temperature on the process of rehydration, and, consequently, on the values of the rehydration indices, may be attributed to an increase in diffusion intensity with temperature (Górnicki, 2011).

Witrowa-Rajchert and Lewicki (2006) compared the volume increase with mass gain during the rehydration of apple, carrot, and potatoes. They stated that the mechanism of water imbibing is substantially influenced by the porosity and chemical composition of the dried material. If the material is characterized by a high degree of porosity then water should fill the pores and the gain in its volume should be either low or entirely absent. In the case of low porosity, and the presence of biopolymers, water penetrating into the matrix of a solid causes swelling and an increase in the volume of the material. Hence, the process of water absorption during rehydration consists of filling the air spaces formed upon drying or in penetrating into the matrix of a solid body, depending on the type of the material used, namely its chemical composition. Dried apples are very porous, hence their mass gain is much faster than the volume increase. The absorption of water by polymers was demonstrated. A more rapid gain in mass than volume lead to a rapid dissolution of low-molecular weight compounds, which may be in an amorphous state, and to a structural collapse at the initial stages of the rehydration process. Amorphous regions of the solid components are the most accessible to the rehydrating medium (Lewicki et al., 1997).

MLP 3-5-1 and MLP 3-4-1 were used to describe all tested rehydration indices $R I_{1}, R I_{2}, R I_{3}, R I_{4}$, and the WAC rehydration index, respectively (Table 2 ). Hidden and output layers with a log-sigmoid transfer function ("logsig") (hidden layer for $R I_{1}, R I_{3}, R I_{4}$, WAC):

$$
\mathrm{F}(x)=\frac{1}{1+\exp ^{-\beta x}},
$$

hyperbolic tangent sigmoid transfer function ("tansig") (hidden layer for $R I_{2}$ and output layer for $R I_{1}, R I_{3}, \mathrm{WAC}$ ):

$$
\mathrm{F}(x)=\frac{2}{1+\exp ^{-\beta x}}-1,
$$

linear transfer function ("purelin") (output layer for $R I_{2}$, $\left.R I_{4}\right)$ :

Table 2. Parameters of neural networks describing rehydration indices

\begin{tabular}{lccccc}
\hline Rehydration index & \multicolumn{3}{c}{ Regression coefficient $\mathrm{R}$} & \multicolumn{2}{c}{ Transfer function } \\
\cline { 2 - 6 } and ANN form & training set & test set & validation set & hidden layer & output layer \\
\hline$R I_{1}$, MLP 3-5-1 & 0.9530 & 0.9665 & 0.9882 & logsig & tansig \\
$R I_{2}$, MLP 3-5-1 & 0.9462 & 0.9721 & 0.9584 & tansig & purelin \\
$R I_{3}$, MLP 3-5-1 & 0.9528 & 0.9478 & 0.9370 & logsig & tansig \\
$R I_{4}$, MLP 3-5-1 & 0.9347 & 0.9347 & 0.9571 & logsig & purelin \\
WAC, MLP 3-4-1 & 0.9493 & 0.9395 & 0.9499 & logsig & tansig \\
\hline
\end{tabular}




$$
\mathrm{F}(x)=a x+b,
$$

where: $x$ is the weighted sum of the input, were used for the prediction of rehydration indices $R I_{1}, R I_{2}, R I_{3}, R I_{4}$, WAC (Table 2).

The "trainlm" (Levenberg-Marquardt) training function and "learngdm" (gradient descent with momentum weight and bias learning function) adaptation learning function were used in this study (Fig. 4).

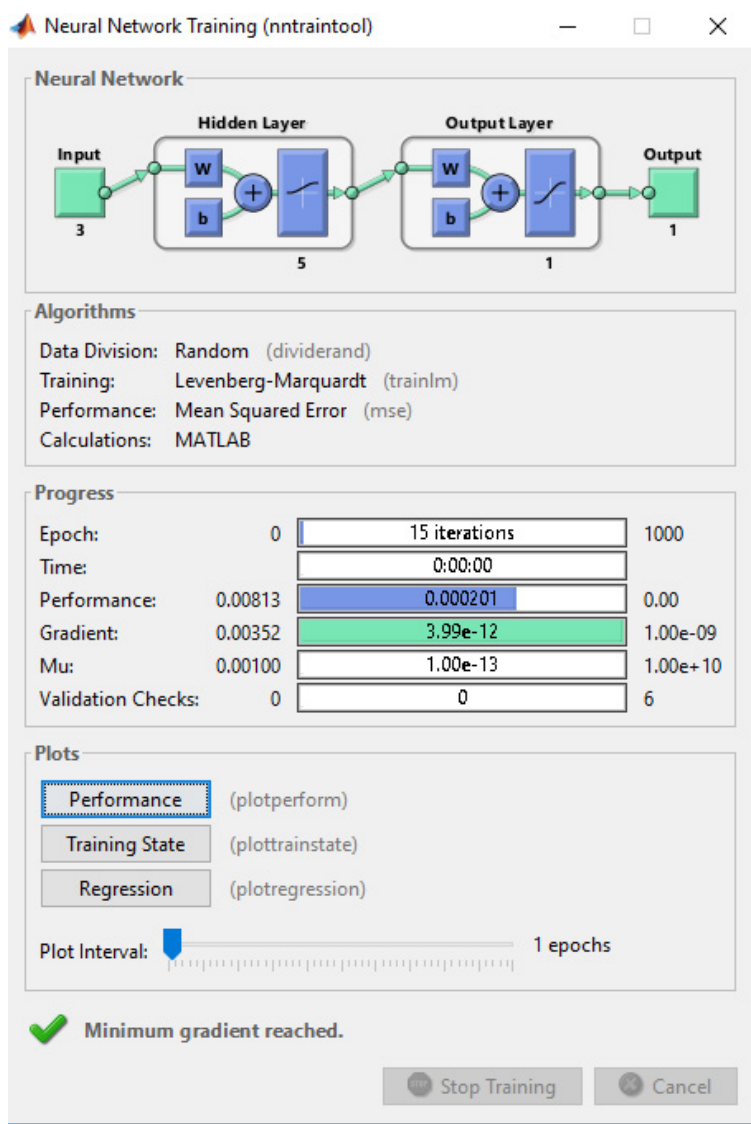

Fig. 4. Neural network training window (for $R I_{1}$ ).

Table 2 presents the parameters of each neural network. The highest values of the correlation coefficient were obtained for the neural networks describing rehydration indices $R I_{1}$ and $R I_{2}$ (validation: 0.988 and 0.958 , respectively.

Weights: $D_{1 i}, D_{2 i}, D_{3 i}$ and bias $D_{4 i}$ in the transfer function for each ANN are presented in Table 3 for the algorithm with three neurons.

The neural networks presented in the work, used for the description of the rehydration indices (respective Eqs (11)(13) and weights and biases from Table 3) are not difficult to use. These models produce good results with regard to rehydration indices calculations. The results of the statistical analysis are presented in Table 4. The obtained values of correlation coefficients $\mathrm{R}$ were high (the highest value for index $R I_{1}$ ), and were within the range of 0.9385 - 0.9608. The lowest MBE values were obtained for net- works describing rehydration indices $R I_{1}$ and $R I_{4}: 0.00019$ and -0.00020 , respectively. The lowest values of RMSE were obtained for neural networks describing rehydration indices $R I_{2}$ and $R I_{4}: 0.0106$ and 0.0109 , respectively, while networks describing rehydration indices WAC and $R I_{3}$ had the highest values. The lowest values of $\chi^{2}$ were obtained for the neural networks describing rehydration indices $R I_{2}$ and $R I_{4}: 0.00013$ and 0.00015 , respectively, while the highest values were obtained for the neural networks describing rehydration indices $R I_{1}$ and $R I_{3}: 0.00025$ and 0.00060 , respectively. The lowest values of t-stat were obtained for neural networks describing rehydration indices $R I_{1}, R I_{4}$ and $R I_{3}$, equal to $0.0647,0.0924$ and 0.1079 , respectively, while the highest values were obtained for neural networks describing the rehydration indices $R I_{2}$ and WAC -0.2337 and 0.6685 , respectively. These results demonstrate that all of the ANNs, which were utilized in this research, sufficiently predicted the rehydration indices behaviour.

In the backward stepwise method, used in this study, three models (for each rehydration indices) were generated, using only two of the variables as inputs. The omitted variable for which the resulting models gave the largest error is the most important one. Table 5 presents the backward stepwise result in which three models were generated using two of the available variables. The R, MSE, RMSE, $\chi^{2}$ and $t$-stat of each model is presented in Table 5 .

The rehydration temperature has the greatest impact on all of the rehydration indices, with the exception of the errors of $t$-stat $T_{r}$, for which it occupied the 2 nd (indices $R I_{4}$, WAC) or 3rd (index $R I_{3}$ ) position. The significant impact of the rehydration temperature on all of the tested rehydration indices is shown in Figs 1-3.

The drying temperature (with the exception of the MSE error) has a lower impact on the rehydration index $R I_{1}$ than $T_{r}$. The same applies to index $R I_{2}$ (with the exception of $\mathrm{R}$ and RMSE errors). The rehydration index $R I_{3}$ is influenced to a lesser extent by the velocity of the drying air ( $t$-stat error indicates the greatest influence of $v$ ) than by $T_{r}$, while index $R I_{4}$ is influenced to a lesser extent by the drying temperature than by $T_{r}$ (with the exception of MSE and $t$-state errors). $T_{r}$ has the greatest influence on the WAC rehydration index (with the exception of MBE and $t$-stat errors), followed by the velocity of the drying air, and $T_{d}$, which has the lowest influence on WAC.

\section{CONCLUSIONS}

1. The present study showed that the drying temperature, drying air velocity and rehydration temperature all had an effect on the rehydration indices tested. The highest values of the rehydration indices: $R I_{1}, R I_{2}$, and $R I_{3}$ characterized apples dried at $70^{\circ} \mathrm{C}\left(v=2 \mathrm{~m} \mathrm{~s}^{-1}\right)$ and rehydrated at $70^{\circ} \mathrm{C}$, whereas for the highest value of $R I_{4}: T_{d}=70{ }^{\circ} \mathrm{C}$, $v=0.5 \mathrm{~m} \mathrm{~s}^{-1}, T_{r}=45^{\circ} \mathrm{C}$, and for the highest WAC value: $T_{d}=60^{\circ} \mathrm{C}, v=6 \mathrm{~m} \mathrm{~s}^{-1}, T_{r}=70^{\circ} \mathrm{C}$. 
Table 3. Weights and biases between input and hidden layers and between hidden and output layers

\begin{tabular}{|c|c|c|c|c|c|c|c|}
\hline \multirow{3}{*}{$\begin{array}{l}\text { Rehydration } \\
\text { index }\end{array}$} & \multirow{3}{*}{$\begin{array}{c}\text { No. } \\
\mathrm{i}\end{array}$} & \multicolumn{4}{|c|}{ Weights and biases between input and hidden layers } & \multicolumn{2}{|c|}{$\begin{array}{l}\text { Weights and biases between } \\
\text { hidden and output layers }\end{array}$} \\
\hline & & \multicolumn{3}{|c|}{ Weights } & \multirow{2}{*}{$\frac{\text { Bias }}{D_{4 i}}$} & \multirow{2}{*}{$\begin{array}{c}\text { Weight } \\
W_{i}\end{array}$} & \multirow{2}{*}{$\frac{\text { Bias }}{B_{i}}$} \\
\hline & & $D_{1 i}$ & $D_{2 i}$ & $D_{3 i}$ & & & \\
\hline \multirow{5}{*}{$R I_{1}$} & 1 & 2.2263 & -5.0363 & -2.674 & -3.8937 & 2.1603 & \multirow{5}{*}{-2.4357} \\
\hline & 2 & 1.4073 & -2.8087 & 4.3445 & -4.9905 & -1.9542 & \\
\hline & 3 & -1.1614 & 1.1078 & 2.9658 & 1.6996 & 4.3315 & \\
\hline & 4 & 8.9821 & 4.5336 & -2.799 & -0.0285 & 1.3050 & \\
\hline & 5 & 3.1877 & 2.0492 & 2.6279 & 5.0453 & -1.2892 & \\
\hline \multirow{5}{*}{$R I_{2}$} & 1 & 0.91143 & -0.27934 & -0.6559 & -1.2366 & 1.8747 & \multirow{5}{*}{0.4334} \\
\hline & 2 & -0.8299 & -0.0402 & 2.7575 & -2.0663 & -0.4097 & \\
\hline & 3 & -1.4268 & 0.30478 & 5.0284 & 0.8122 & 0.6729 & \\
\hline & 4 & 4.7272 & 3.8261 & 1.9944 & 3.7159 & -0.3895 & \\
\hline & 5 & -1.6374 & 2.1463 & 3.4860 & 5.1930 & 0.7983 & \\
\hline \multirow{5}{*}{$R I_{3}$} & 1 & 3.2503 & -0.2115 & -2.0313 & -3.2770 & 2.6335 & \multirow{5}{*}{-1.5037} \\
\hline & 2 & -1.8275 & 0.0702 & 4.1950 & -3.8481 & -1.2753 & \\
\hline & 3 & -1.3689 & -0.00198 & 9.0181 & 1.8186 & 1.4881 & \\
\hline & 4 & 6.3106 & 6.2380 & 3.5614 & 5.6725 & -1.0460 & \\
\hline & 5 & -2.1551 & 4.6745 & 5.8387 & 10.0079 & 1.2407 & \\
\hline \multirow{5}{*}{$R I_{4}$} & 1 & 6.6225 & -0.3203 & -5.8576 & -4.2217 & 1.1220 & \multirow{5}{*}{0.0176} \\
\hline & 2 & -4.6245 & -0.4371 & 11.6314 & -8.5315 & -1.0395 & \\
\hline & 3 & -0.6546 & 0.9401 & 8.2053 & 2.2298 & 1.4923 & \\
\hline & 4 & 1.5662 & 4.6846 & -1.1206 & 4.5055 & 2.5264 & \\
\hline & 5 & 3.2771 & 2.5519 & 0.1810 & 2.3151 & -3.7055 & \\
\hline \multirow{4}{*}{ WAC } & 1 & 4.412 & -3.6328 & -3.4425 & -4.5383 & -2.1287 & \multirow{4}{*}{-2.2130} \\
\hline & 2 & -2.5595 & 1.0019 & -7.4127 & 1.5151 & -2.7469 & \\
\hline & 3 & 1.1076 & -4.1162 & -1.7051 & -2.2043 & 2.6620 & \\
\hline & 4 & -1.4307 & 1.7808 & -6.7500 & 4.6618 & 4.1876 & \\
\hline
\end{tabular}

Table 4. Comparison between the results of statistical analyses concerning the modelling of rehydration indices

\begin{tabular}{cccccc}
\hline $\begin{array}{c}\text { Rehydra- } \\
\text { tion index }\end{array}$ & $\mathrm{R}$ & $\mathrm{MBE}$ & $\mathrm{RMSE}$ & $\chi^{2}$ & $t$-stat \\
\hline$R I_{1}$ & 0.9608 & 0.0002 & 0.0144 & 0.0003 & 0.0647 \\
$R I_{2}$ & 0.9515 & 0.0005 & 0.0106 & 0.0001 & 0.2337 \\
$R I_{3}$ & 0.9498 & 0.0005 & 0.0227 & 0.0006 & 0.1079 \\
$R I_{4}$ & 0.9385 & -0.0002 & 0.0109 & 0.0002 & 0.0924 \\
$\mathrm{WAC}$ & 0.9475 & -0.0018 & 0.0123 & 0.0002 & 0.6685 \\
\hline
\end{tabular}

2. The proposed ANN (MLP 3-5-1 (rehydration indices: $R I_{1}-R I_{4}$ ) and MLP 3-4-1 (WAC)) accurately describe the properties of apple cubes dried at different drying process parameters $(\mathrm{R} \in(0.9385-0.9608), \mathrm{MBE} \in(-0.0018$ $0.0005), \quad \operatorname{RMSE} \in(0.0106-0.0227), \quad \chi^{2} \in(0.0001-0.0006)$, $t$-stat $\in(0.0647-0.6685))$, rehydrated at different temperatures. The proposed neural networks describe the rehydration index $R I_{1}$ for $T_{d} \in\left[50-70{ }^{\circ} \mathrm{C}\right], v \in[0.01-2 \mathrm{~m}$ $\left.\mathrm{s}^{-1}\right], T_{r} \in\left[20-95^{\circ} \mathrm{C}\right]$, rehydration indices $R I_{2}, R I_{3}$ and $R I_{4}$ for $T_{d} \in\left[50-70^{\circ} \mathrm{C}\right], v \in\left[0.01-6 \mathrm{~m} \mathrm{~s}^{-1}\right], T_{r} \in\left[20-95^{\circ} \mathrm{C}\right]$, and the WAC rehydration index for $T_{d} \in\left[50-70^{\circ} \mathrm{C}\right], v \in\left[2-6 \mathrm{~m} \mathrm{~s}^{-1}\right]$, 
Table 5. Sensitivity analysis for rehydration indices - stepwise method

\begin{tabular}{|c|c|c|c|c|c|c|}
\hline $\begin{array}{l}\text { Rehydration } \\
\text { index }\end{array}$ & $\begin{array}{l}\text { Omitted } \\
\text { parameter }\end{array}$ & $\mathrm{R}$ & MBE & RMSE & $\chi^{2}$ & $t$-stat \\
\hline \multirow{4}{*}{$R I_{1}$} & $T_{d}$ & $0.8371^{(2)^{*}}$ & $0.00175^{(3)}$ & $0.02848^{(2)}$ & $0.00097^{(2)}$ & $0.30800^{(2)}$ \\
\hline & $v$ & $0.9462^{(3)}$ & $0.00091^{(2)}$ & $0.01690^{(3)}$ & $0.00034^{(3)}$ & $0.27045^{(3)}$ \\
\hline & $T_{r}$ & $0.5828^{(1)}$ & $-0.00504^{(1)}$ & $0.04262^{(1)}$ & $0.00217^{(1)}$ & $0.59581^{(1)}$ \\
\hline & $T_{d}$ & $0.9481^{(3)}$ & $-0.00018^{(2)}$ & $0.01061^{(3)}$ & $0.00013^{(2)}$ & $0.08477^{(2)}$ \\
\hline \multirow[t]{2}{*}{$R I_{2}$} & $v$ & $0.9466^{(2)}$ & $0.00009^{(3)}$ & $0.01069^{(2)}$ & $0.00013^{(2)}$ & $0.04241^{(3)}$ \\
\hline & $T_{r}$ & $0.9330^{(1)}$ & $0.00028^{(1)}$ & $0.01175^{(2)}$ & $0.00016^{(1)}$ & $0.12092^{(1)}$ \\
\hline \multirow{3}{*}{$R I_{3}$} & $T_{d}$ & $0.8763^{(3)}$ & $-0.00193^{(3)}$ & $0.03411^{(3)}$ & $0.00136^{(3)}$ & $0.28330^{(2)}$ \\
\hline & $v$ & $0.8208^{(2)}$ & $-0.00247^{(2)}$ & $0.03687^{(2)}$ & $0.00159^{(2)}$ & $0.33589^{(1)}$ \\
\hline & $T_{r}$ & $0.5453^{(1)}$ & $-0.00308^{(1)}$ & $0.05692^{(1)}$ & $0.00378^{(1)}$ & $0.27114^{(3)}$ \\
\hline \multirow{3}{*}{$R I_{4}$} & $T_{d}$ & $0.7887^{(2)}$ & $-0.00103^{(3)}$ & $0.01938^{(2)}$ & $0.00049^{(2)}$ & $0.26610^{(3)}$ \\
\hline & $v$ & $0.9080^{(3)}$ & $0.00110^{(2)}$ & $0.01322^{(3)}$ & $0.00023^{(3)}$ & $0.41931^{(1)}$ \\
\hline & $T_{r}$ & $0.1469^{(1)}$ & $-0.00181^{(1)}$ & $0.03158^{(1)}$ & $0.00129^{(1)}$ & $0.28705^{(2)}$ \\
\hline \multirow{3}{*}{ WAC } & $T_{d}$ & $0.8184^{(3)}$ & $-0.00070^{(3)}$ & $0.02195^{(3)}$ & $0.00061^{(3)}$ & $0.14188^{(3)}$ \\
\hline & $v$ & $0.7450^{(2)}$ & $-0.00233^{(1)}$ & $0.02593^{(2)}$ & $0.00085^{(2)}$ & $0.40428^{(1)}$ \\
\hline & $T_{r}$ & $0.4586^{(1)}$ & $0.00169^{(2)}$ & $0.03374^{(1)}$ & $0.00143^{(1)}$ & $0.22376^{(2)}$ \\
\hline
\end{tabular}

*Parameter impact classification.

$T_{r} \in\left[20-95^{\circ} \mathrm{C}\right]$. A sensitivity analysis of the ANN (backward stepwise method) demonstrates that $T_{r}$ has the greatest impact on all of the rehydration indices, followed by $T_{d}$ (for rehydration indices $R I_{1}, R I_{2}, R I_{4}$ ), and $v$ (for rehydration indices $R I_{3}$ and WAC).

Conflict of interest: The authors declare that they have no conflict of interest.

Compliance with ethical requirements: This study does not contain any experiment involving human or animal subjects.

\section{REFERENCES}

Antonio G.C., Alves D.G., Azoubel P.M., Murr F.E.X., and Park K.J., 2008. Influence of osmotic dehydration and high temperature short time processes on dried sweet potato (Ipomoea batatas Lam.). J. Food Eng., 84, 375-382. https:// doi.org/10.1016/j.jfoodeng.2007.05.033

Aral S. and Beșe A.V., 2016. Convective drying of hawthorn fruit (Crataegus spp.): Effect of experimental parameters on drying kinetics, colour, shrinkage, and rehydration capacity. Food Chem., 210, 577-584. https://doi.org/10.1016/j. foodchem.2016.04.128

Askari G.R., Emam-Djomeh Z., and Mousavi S.M., 2009. An investigation of the effects of drying methods and conditions on drying characteristics and quality attributes of agricultural products during hot air and hot air/microwave - assisted dehydration. Drying Technol., 27, 831-841. https://doi.org/10.1080/07373930902988106

Atarés L., Chiralt A., and Gonzáles-Martinez C., 2008. Effect of solute on osmotic dehydration and rehydration of vacu- um impregnated apple cylinders (cv. Granny Smith). J. Food Eng., 89, 49-56. https://doi.org/10.1016/j. jfoodeng.2008.04.002

Beigi M., 2017. Thin layer drying of wormwood (Artemisa absinthium L.) leaves: dehydration characteristics, rehydration capacity and energy consumption. Mass Transfer, 53, 7112718. https://doi.org/10.1007/s00231-017-2018-3

Benseddik A., Azzi A., Zidoune M.N., Khanniche R., and Besombes C., 2018. Empirical and diffusion models of rehydration process of differently dried pumpkin slices. J. Saudi Soc. Agric. Sci. (in press). https://doi.org/10.1016/j. jssas.2018.01.003

Cheng W.M., Raghavan G.S., Ngadi M., and Wang N., 2006. Microwave power control strategies on the drying process. II. Phase-controlled and cycle-controlled microwave/air drying. J. Food Eng., 76, 195-201. https://doi.org/10.1016/j. jfoodeng.2005.05.007

Dimopoulos Y., Bourret P., and Lek S., 1995. Use of some sensitivity criteria for choosing networks with good generalization ability. Neural Process. Lett., 2(6), 1-4. https://doi.org/10.1007/bf02309007

Doymaz I., 2017. Drying kinetics, rehydration and colour characteristics of convective hor-air drying of carrot slices. Heat Mass Trasf., 53, 25-35. https://doi.org/10.1007/ s00231-016-1791-8

Ergün K., Çalişkan G., and Dirim S. N., 2016. Determination and rehydration kinetics of freeze dried kiwi (Actinidia deliciosa) slices. Heat Mass Transf., 52, 2697-2705. https:// doi.org/10.1007/s00231-016-1773-x

Farkas B.E. and Singh R.P. 1991. Physical properties of airdried and freeze-dried chicken white meat. J. Food Sci., 56(3), 611-615. https://doi.org/10.1111/j.1365-2621.1991. tb05341.x

Fang S., Wang Z., Hu X., and Datta A.K., 2009. Hot-air drying of whole fruit Chinese jujube (Zizyphus jujuba Miller): 
physicochemical properties of dried products. Int. J. Food Sci. Technol., 44, 1415-1421. https://doi. org/10.1111/j.1365-2621.2009.01972.x

Femenia A., Bestard M.J., Sanjuan N., Rossselló C., and Mulet A., 2000. Effect of rehydration temperature on cell wall components of broccoli (Brassica oleracea L. var. Italica) plant tissues. J. Food Eng., 46, 157-163. https://doi. org/10.1016/s0260-8774(00)00078-9

Figiel A., 2007. Dehydration of apples by a combination of convective and vacuum-microwave drying. Pol. J. Food Nutr. Sci., 57(4(A)), 131-135.

Figiel A., Szumny A., Gutiérrez-Ortíz A., and CarbonellBarrachina Á.A., 2010. Composition of oregano essential oil (Origanum vulgare) as affected by drying method. J. Food Eng., 98(2), 240-247. https://doi.org/10.1016/j. jfoodeng.2010.01.002

Garcia-Pascual P., Sanjuan N., Bon J., Carreres J.E., and Mulet A., 2005. Rehydration process of Boletus edulis mushroom: characteristics and modelling. J. Sci. Food Agric., 85, 1397-1404. https://doi.org/10.1002/jsfa.2126

Garcia-Pascual P., Sanjuán N., Melis R., and Mulet A., 2006. Morchella esculenta (morel) rehydration process modelling. J. Food Eng., 72, 346-353. https://doi.org/10.1016/j. jfoodeng.2004.12.014

Garson G.D., 1991. Interpreting neural-network connection weights. AI Expert, 6, 46-51.

Gevrey M., Dimopoulos I., and Lek S., 2003. Review and comparison of methods to study the contribution of variables in artificial neural network models. Ecol. Model., 160(3), 249264. https://doi.org/10.1016/s0304-3800(02)00257-0

Górnicki K., 2011. Modelling of selected vegetables and fruits rehydration process (in Polish). Wydawnictwo SGGW, Warsaw, Poland.

Górnicki K. and Kaleta A., 2007. Drying curve modelling of blanched carrot cubes under natural convection condition. J. Food Eng., 82(2), 160-170. https://doi.org/10.1016/j. jfoodeng.2007.02.002

Górnicki K., Kaleta A., Winiczenko R., Chojnacka A., and Janaszek M., 2013. Some remarks on modelling of mass transfer kinetics during rehydration of dried fruits and vegetables. In: Mass Transfer - Advances in sustainable energy and environment oriented numerical modelling (Ed. H. Nakajima), InTech, Rijeka, Croatia. https://doi. org/10.5772/54072

Harnkarnsujarit N., Kawai K., Watanabe M., and Suzuki T., 2016. Effect of freezing on microstructure and rehydration properties of freeze-dried soybean curd. J. Food Eng., 184, 10-20. https://doi.org/10.1016/j.jfoodeng.2016.03.014

Hartigan J.A., 1975. Clustering algorithms. Wiley, New York, USA.

Jayaraman K.S. , Das Gupta D. K., and Babu Rao N., 1990. Effect of pretreatment with salt and sucrose on the quality and stability of dehydrated cauliflower. Int. J. Food Sci. Technol. 25(1), 47-60. https://doi. org/10.1111/j.1365-2621.1990.tb01058.x

Jokić S., Velić D., Bilić M., Lukinac J., Planinić M., and BucićKoijé A., 2009. Influence of process parameters and pre-treatments on quality and drying kinetics of apple samples. Czech J. Food Sci., 27(2), 88-94. https://doi. org/10.17221/170/2008-cjfs
Kaleta A. and Górnicki K., 2010a. Evaluation of drying models of apple (var. Mc Intosh) dried in a convective dryer. Int. J. Food Sci. Technol., 45, 891-898. https://doi. org/10.1111/j.1365-2621.2010.02230.x

Kaleta A. and Górnicki K., 2010b. Some remarks on evaluation of drying models of red beet particles. Energ. Convers. Manag., 51, 2967-2978. https://doi.org/10.1016/j. enconman.2010.06.040

Kaleta A., Górnicki K., Choińska A., and Winiczenko R., 2013a. The effect of drying parameters on the loss of dry matter during the rehydration of dried apples. Agric. Eng., 4, 111-120.

Kaleta A., Górnicki K., Winiczenko R., and Chojnacka A., 2013b. Evaluation of drying models of apple (var. Ligol) dried in a fluidized bed dryer. Energ. Convers. Manage., 67, 179-185. https://doi.org/10.1016/j.enconman.2012.11.011

Kaleta A., Winiczenko R., Choińska A., and Górnicki K., 2014. Determination of the mass and dry matter changes during rehydration of dried apples (in Polish). Postępy Techniki Przetwórstwa Spożywczego, 2, 18-23.

Karam M.C., Petit J., Zimmer D., Djantou E.B., and Scher J., 2016. Effects of drying and grinding in production of fruit and vegetable powders: a review. J. Food Eng., 188, 32-49. https://doi.org/10.1016/j.jfoodeng.2016.05.001

Kaushal P. and Sharma H.K., 2016. Osmo-convective dehydration kinetics of jackfruit (Artocarpus heterophyllus). J. Saudi Soc. Agric. Sci., 15(2), 118-126. https://doi. org/10.1016/j.jssas.2014.08.001

Khazei J. and Mohammadi N., 2009. Effect of temperature on rehydration kinetics of sesame seeds (Sesamum indicum L.). J. Food Eng., 91, 542-552. https://doi.org/10.1016/j. jfoodeng.2008.10.010

Lek S., Belaud A., Baran P., Dimopoulos I., and Delacoste M., 1996. Role of some environmental variables in trout abundance models using neural networks. Aquat. Living Resour., 9(1), 23-29. https://doi.org/10.1051/alr:1996004

Lewicki P.P., 1998. Some remarks on rehydration of dried foods. J. Food Eng., 36, 81-87. https://doi.org/10.1016/ s0260-8774(98)00022-3

Lewicki P.P., Le H.V., and Pomarańska-Lazuka W., 2002. Effect of pre-treatment on convective drying of tomatoes. J. Food Eng., 54, 141-146. https://doi.org/10.1016/ s0260-8774(01)00199-6

Lewicki P.P., Witrowa-Rajchert D., and Mariak J., 1997. Changes of structure during rehydration of dried apples. J. Food Eng., 32, 347-350. https://doi.org/10.1016/ s0260-8774(97)00042-3

Lewicki P.P. and Wiczkowska J., 2006. Rehydration of apple dried by different methods. Int. J. Food Prop., 9, 217-226. https://doi.org/10.1080/10942910600596084

Lin Z.-P., Lee T.-Y., Tsen J.-H., and King V.A.-E., 2007. Dehydration of yam using FIR - assisted freeze drying. J. Food Eng., 79, 1295-1301. https://doi.org/10.1016/j. jfoodeng.2006.04.018

Link J.V., Tribuzi G., and Laurindo J.B., 2017. Improving quality of dried fruits: A comparison between conductive multi-flash and traditional drying methods. LWT-Food Sci. Technol., 84, 717-725. https://doi.org/10.1016/j. lwt.2017.06.045 
Maldonado S., Arnau E., and Bertuzzi M.A., 2010. Effect of temperature and pretreatment on water diffusion during rehydration of dehydrated mangoes. J. Food Eng., 96, 333341. https://doi.org/10.1016/j.jfoodeng.2009.08.017

Markowski M., Bondaruk J., and Blaszczak W., 2009. Rehydration behaviour of vacuum-microwave-dried potato cubes. Drying Technol., 27, 296-305. https://doi. org/10.1080/07373930802606600

Markowski M. and Zielińska M., 2011. Kinetics and water absorption and soluble-solid loss of hot-air-dried carrots during rehydration. Int. J. Food Sci. Technol., 46, 11221128. https://doi.org/10.1111/j.1365-2621.2011.02589.x

Maskan M., 2000. Microwave/air and microwave finish drying of banana. J. Food Eng., 44, 71-78. https://doi.org/10.1016/ s0260-8774(99)00167-3

Mittal G.S., 1996. Computerized control systems in the food industry. Marcel Dekker, Inc., New York, USA.

Moreira R., Chenlo F., Chaguri L., and Fernandes C., 2008. Water absorption, texture, and colour kinetics of air-dried chestnuts during rehydration. J. Food Eng., 86(4), 584-594. https://doi.org/10.1016/j.jfoodeng.2007.11.012

Nathakaranakule A., Jaiboon P., and Soponronnarit S., 2010. Far-infrared radiation assisted drying of longan fruit. J. Food Eng., 100, 662-668. https://doi.org/10.1016/j. jfoodeng.2010.05.016

Nayak C.A., Suguna K., and Rastogi N.K., 2006. Combined effect of gamma-irradiation and osmotic treatment on mass transfer during rehydration of carrots. J. Food Eng., 74(1), 134-142. https://doi.org/10.1016/j.jfoodeng.2005.02.020

Nowak D., Piechucka P., Witrowa-Rajchert D., and Wiktor A., 2016. Impact of material structure on the course of freezing and freeze-drying and on the properties of dried substance, as exemplified by celery. J. Food Eng., 180, 22-28. https:// doi.org/10.1016/j.jfoodeng.2016.01.032

Pervin S., Islam M.S., and Islam M.N., 2008. Study on rehydration characteristics of dried lablab bean (Lablal purpureus) seeds. Asian J. Agri. Rural Dev., 6(1\&2), 157-163. https:// doi.org/10.3329/jard.v6i1.1673

Rastogi N.K., Nayak C.A., and Raghavarao K.S.M.S., 2004. Influence of osmotic pre-treatments on rehydration characteristics of carrots. J. Food Eng., 65(2), 287-292. https://doi. org/10.1016/j.jfoodeng.2004.01.027

Ravindra M.R. and Chattopadhyay P.K., 2000. Optimisation of osmotic preconcentration and fluidised bed drying to produce dehydrated quick-cooking potato cubes. J. Food Eng., 44, 5-11. https://doi.org/10.1016/ s0260-8774(99)00159-4

Redgewell R.J., Curti D., and Gehin-Delval C., 2008. Physicochemical properties of cell wall materials from apple, kiwifruit and tomato. Eur. Res. Technol., 227, 607618. https://doi.org/10.1007/s00217-007-0762-1

Rząca M., 2009. Studies on the use of infrared and microwave radiation for drying apples (in Polish). PhD thesis, WULS, Warsaw, Poland.
Said L.B.H., Bellagha S., and Allaf K., 2015. Measurements of texture, sorption isotherms and drying/rehydration kinetics of dehydrofrozen-textured apple. J. Food Eng., 165, 22-33. https://doi.org/10.1016/j.jfoodeng.2015.04.029

Seguí L., Fito P.J., and Fito P., 2013. A study on the rehydration ability of isolated apple cells after osmotic dehydration treatments. J. Food Eng., 115, 145-153. https://doi. org/10.1016/j.jfoodeng.2012.08.038

Seremet (Ceclu) L., Botez E., Nistor O.-V., Andronoiu D.G., and Mocanu G.-D., 2016. Effect of different drying methods on moisture ratio and rehydration of pumpkin slices. Food Chem., 195, 104-109. https://doi.org/10.1016/j. foodchem.2015.03.125

Sharma G.P. and Prasad S., 2006. Optimization of process parameters for microwave drying of garlic cloves. J. Food Eng., 75, 441-446. https://doi.org/10.1016/j. jfoodeng.2005.04.029

Silva B.G., Fileti A.M.F., Foglio M.A., de Tarso Vieira Rosa P., and Taranto O.P., 2017. Effects of different drying conditions on key quality parameters of pink peppercorns (Schinus terebinthifolius Raddi). J. Food Quality, 3152797. https://doi.org/10.1155/2017/3152797

Stępień B., 2008. Rehydration of carrot dried using various methods. Acta Agrophys., 2008, 11(1), 239-251

Verma R.C. and Gupta A., 2004. Effect of pre-treatments on quality of solar-dried amla. J. Food Eng., 65, 397-402. https://doi.org/10.1016/j.jfoodeng.2004.02.010

Winiczenko R., Górnicki K., Kaleta A., and JanaszekMańkowska M., 2018. Optimisation of ANN topology for predicting the rehydrated apple cubes colour change using RSM and GA. Neural Comput. Appl., 30(6), 1795-1809. https://doi.org/10.1007/s00521-016-2801-y

Witrowa-Rajchert D., 1999. Rehydration as an index of changes occurring in plant tissue during drying (in Polish). Fundacja "Rozwój SGGW", Warszawa, Poland.

Witrowa-Rajchert D., 2003. Mathematical modeling of the rehydration process of dried apple tissue. Acta Agrophys., 82, 193-204.

Witrowa-Rajchert D. and Lewicki P.P., 2006. Rehydration properties of dried plant tissues. Int. J. Food Sci. Technol., 41, 1040-1046. https://doi.org/10.1111/j.1365-2621.2006. 01164.x

Witten I.H. and Frank E., 2005. Data Mining: Practical machine learning tools and techniques. Morgan Kaufmann Publishers, New York, USA.

Zhang L., Huang X., Miao S., Zeng S., Zhang Y., and Zheng B., 2016. Influence of ultrasound on the rehydration of dried sea cucumber (Stichopus japonicus). J. Food Eng., 178, 203-211. https://doi.org/10.1016/j.jfoodeng.2016.01.024

Zhang M., Wang C., Ma X., and Li C., 1994. Study of rehydration before eating on dehydrated vegetables. In: Developments in Food Engineering. (Eds T. Yano, R. Matsuno, K. Nakamura) Springer, Boston, MA. 